\title{
Metahemoglobinemia detected during general anesthesia - a case report
}

\begin{abstract}
Methaemoglobinaemia can cause significant tissue hypoxia, leading to severe, potentially life-threatening clinical features and/or death. We describe the anesthetic care of a patient with acquired methemoglobinemia related to recreational drug use. As was the case in this patient, the diagnosis may first be made intraoperatively. A 38-year-old man who had to have emergency surgery due to traumatic colonic perforation. At the physical examination presented a blue skin colour, cyanosis, normal blood pressure and heart rate, respiratory rate of $18 /$ min. Pulse oximetry revealed an oxygen saturation $\left(\mathrm{SpO}_{2}\right)$ of $85 \%$ with a $36 \%$ $\mathrm{FIO}_{2}$, normal chest x-ray. The first arterial blood sample had a chocolate brown colour and the co-oximeter showed a methemoglobin level of $31 \%$. Methylene blue was administrated. Pulse oximetry revealed an increase in saturation to $100 \%$. One day after the surgery, we asked the patient for the causative agent of his Metahemoglobinemia and we found out that he had taken amyl nitrite (poppers).
\end{abstract}

Keywords: equipment pulse oximeter, oxygen cianosis, oxygen transport
Volume 2 Issue 3 - 2015

\section{Henriette Montalvo}

Hospital Santa Creu i Sant Pau - Barcelone, Spain

Correspondence: Henriette Montalvo, Hospital Santa Creu i Sant Pau - Barcelone, Sant Antoni Maria Claret, 16708025 Barcelona, Spain, Tel 689344109, Email henriette08@hotmail.com

Received: March 10, 2015 | Published: June 03, 2015

\section{Background}

Methemoglobinemia is a hereditary or adquired disorder characterized by the presence of higher than normal levels of methemoglobin $\left(\left[\mathrm{Fe}^{3+}\right]\right.$ rather than ferrous $\left[\mathrm{Fe}^{2+}\right]$ hemoglobin in the blood. Methemoglobinemia may occur as an idiosyncratic reaction to an exposure to drugs such as nitrites.

\section{Case report}

We present this case of a 38-year-old man who had to have emergency surgery due to traumatic colonic perforation. On examination the patient had a "blue" skin colour, normal blood pressure and heart rate and a respiratory rate of $18 / \mathrm{min}$. Pulse oximetry revealed an oxygen saturation $\left(\mathrm{SpO}_{2}\right)$ of $85 \%$ even after a $36 \% \mathrm{FIO}_{2}$.
Chest x-ray was normal. After tracheal intubation and controlled ventilation with $\mathrm{FiO}_{2}, 50 \%$ an arterial catheter was placed for continuous hemodynamic monitoring and arterial blood gas analysis. The first arterial blood sample had a chocolate brown colour and the CO-Oximeter showed a methemoglobin level of $31 \%$. Methylene blue $(1 \mathrm{mg} / \mathrm{kg}$ over 3 minutes) was administrated. The methemoglobin level dropped to $13,6 \%$. A second dose of methylene blue was give achieving a further reduction and the cyanosis disappeared. Pulse oximetry revealed an increase in saturation to $100 \%$ (Table 1). The operation was completed without any decrease in oxygen saturation and no other complications. One day after the surgery, we asked the patient for the causative agent of his Metahemoglobinemia and we found out that he had taken amyl nitrite.

Table I Pulse oximetry revealed an increase in saturation to $100 \%$

\begin{tabular}{llll}
\hline & After induction & Methylene blue I mg/kg first administration & Methylene blue Img/kg first administration \\
\hline $\mathbf{p H}$ & 7,36 & 7,31 & 7,3 \\
$\mathrm{SaO}_{2}$ & $97 \%$ & $98,6 \%$ & $97,3 \%$ \\
$\mathrm{PaO}_{2}$ & $285 \mathrm{mmHg}$ & $268 \mathrm{mmHg}$ & $312 \mathrm{mmHg}$ \\
$\mathrm{PaCO}_{2}$ & $32 \mathrm{mmHg}$ & $35 \mathrm{mmHg}$ & $37 \mathrm{mmHg}$ \\
$\mathbf{O}_{2} \mathrm{Hb}$ & $66,9 \%$ & $85,2 \%$ & $94,4 \%$ \\
MetHb & 31 & $13,6 \%$ & $3,0 \%$ \\
Pulse Oximeter & $86 \%$ & $95 \%$ & $100 \%$ \\
\hline
\end{tabular}

\section{Discussion}

Methaemoglobinaemia can cause significant tissue hypoxia, leading to severe, potentially life-threatening clinical features and/ or death is the most common cause of hemoglobin-specific cyanosis and it can occur either in congenital or acquired forms. ${ }^{1}$ Amyl nitrite, benzocaine, dapsone, lidocaine, nitroglycerin, phenytoin, primaquine and sulfonamides have all been implicated. Aniline derivatives, lidocaine, prilocaine and nitrites are the most common methemoglobinemic inducing drugs. Over recent years there have been increasing reports of Methaemoglobinaemia related to recreational drug use.

The diagnosis of MetHb should be suspected in patients that appear cyanotic and have a low pulse oximetry reading with no apparent respiratory or cardiovascular problems to explain the low $\mathrm{O}_{2}$ saturation. Arterial blood gas analysis will reveal a normal $\mathrm{PaO}_{2}$ that is not consistent with the pulse-oximeter measured saturation. The diagnosis is confirmed by measurement of MetHb levels using co-oximetry. The co-oximetry has the ability to measure light absorbance at the four different wavelengths that characterize deoxyhemoglobin, oxyhemoglobin, carboxyhemoglobin, and methemoglobin. The peak absorbance of light at $630 \mathrm{~nm}$ is used to characterize MetHb. The clinical signs of methemoglobinemia are a result of the inability of methemoglobin to bind oxygen. Clinical severity of the presenting symptoms and signs depends on the blood level of methemoglobin. Levels greater than $15 \%$ are associated with cyanosis. Levels between 20 and $45 \%$ present with signs symptoms of headache, lethargy, taquicardia, weakness, and dizziness. Dyspnea, 
acidosis, cardiac dysrhytmias, heart failure, seizures, and coma may occur at levels exceeding $45 \%$. A high mortality rate is associated with methemoglobin levels above $70 \%$. Apart from the removal of the drug, the treatment of choice is the i.v administration of methylene blue.

\section{Conclusion}

The treatment of choice for symptomatic methemoglobinemia is immediate therapy with IV methylene blue and identification and removal of the offending drug or toxin. Methylene blue acts as a cofactor for NADPH MetHb reductase, the alternative hemoglobin reduction pathway, and greatly increases the enzymatic reduction of MetHb through this pathway. Methylene blue is administered i.v in a dose of 1 to $2 \mathrm{ml} / \mathrm{Kg}$ of $1 \%$ solution; this dose may be repeated in 30 to 60 minutes if the methemoglobinemia persists. Anecdotal reports suggest additional therapies to increase $\mathrm{O}_{2}$ delivery, such as homologous transfusions, exchange transfusions, and hyperbaric $\mathrm{O}_{2}$ therapy.

\section{Acknowledgements}

None.

\section{Conflicts of interest}

The authors declare that there are no conflicts of interest.

\section{Funding}

None.

\section{References}

1. Hunter L, Gordge L, Dargan PI, Wood DM. Methaemoglobinaemia associated with the use of cocaine and volatile nitrites as recreational drugs: a review. Br J Clin Pharmacol. 2011;72(1):18-26. 